Provided for non-commercial research and education use. Not for reproduction, distribution or commercial use.

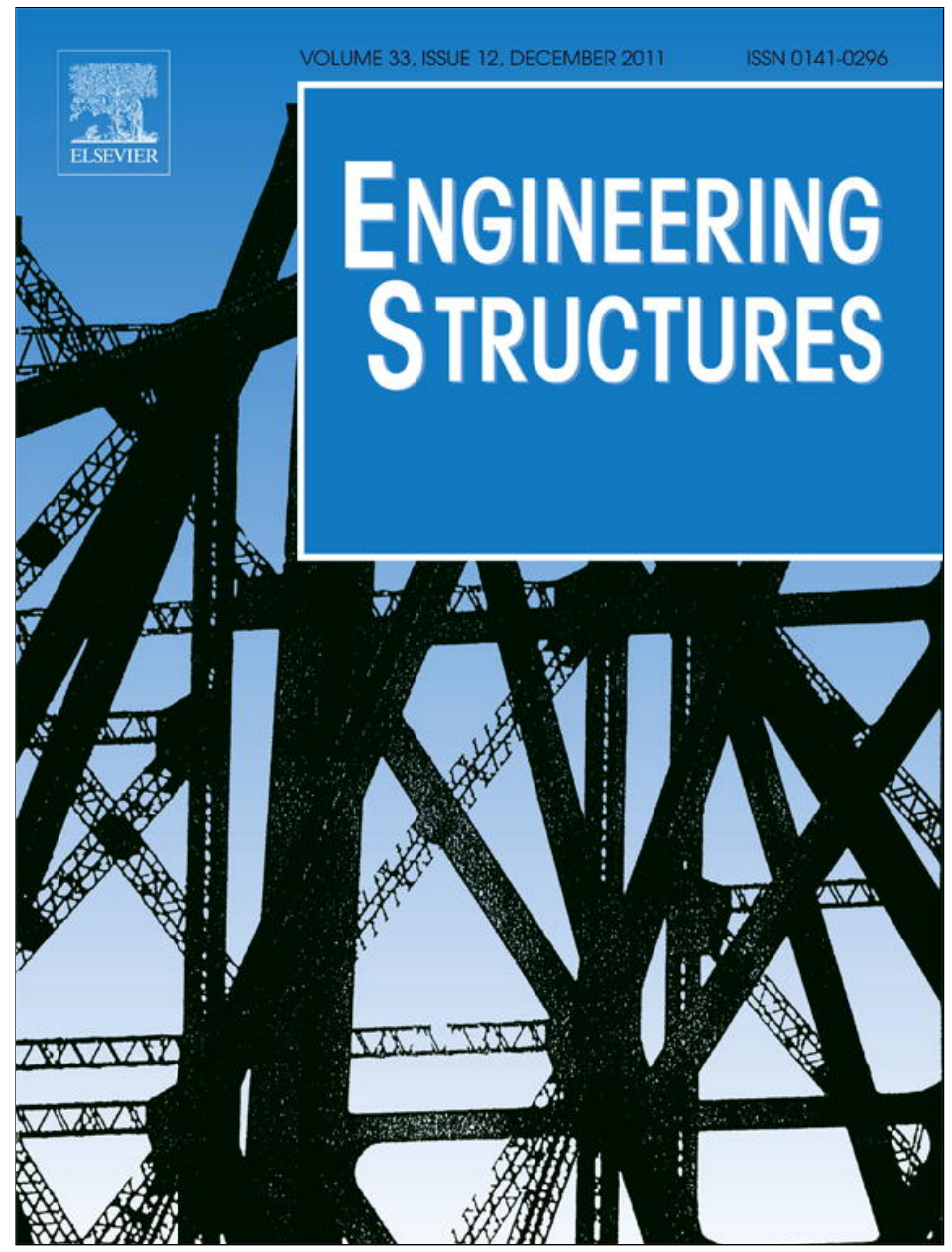

This article appeared in a journal published by Elsevier. The attached copy is furnished to the author for internal non-commercial research and education use, including for instruction at the authors institution and sharing with colleagues.

Other uses, including reproduction and distribution, or selling or licensing copies, or posting to personal, institutional or third party websites are prohibited.

In most cases authors are permitted to post their version of the article (e.g. in Word or Tex form) to their personal website or institutional repository. Authors requiring further information regarding Elsevier's archiving and manuscript policies are encouraged to visit:

http://www.elsevier.com/copyright 


\section{A compression-tension concrete damage model, applied to a wind turbine reinforced concrete tower}

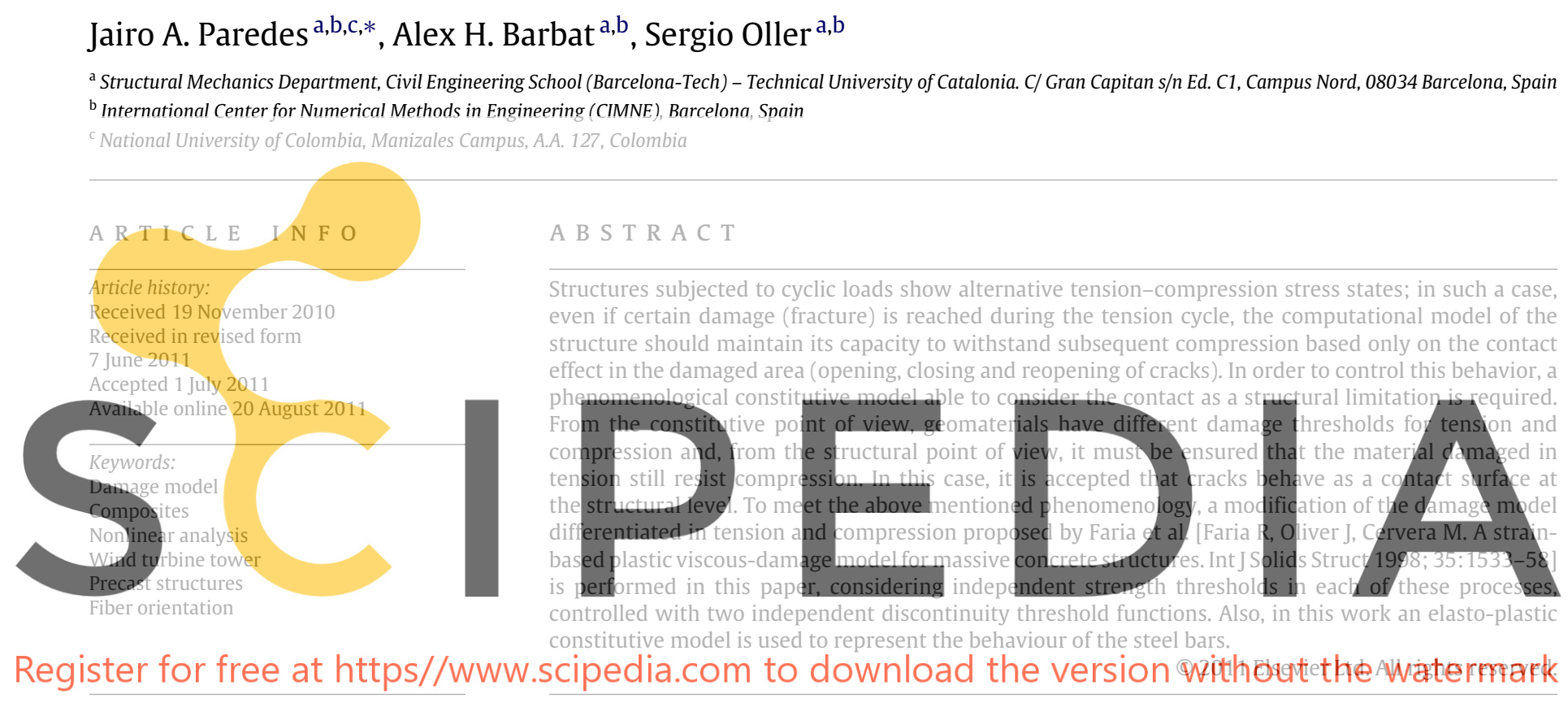

\section{Introduction}

The increase in the size of wind turbines requires an increase in the height of their towers [1]. Traditionally, wind turbines have been supported by steel conical frustum shaped towers of about 20-30 m assembled in situ. The increase in height required an increase of the thickness of the tower, with the consequent problem of manufacturing and transportation of the steel parts. Moreover, Harte and Van Zijl [2], established that steel tube towers higher than $85 \mathrm{~m}$ are no longer able to assure adequate behaviour of the vibrations induced by the wind turbine. Petcu and MariBernat [3] established that steel towers can be used only up to $80 \mathrm{~m}$ high. Due to this fact and to the maintenance cost of steel towers, reinforced concrete began to be used in recent years for these towers. The height of the reinforced concrete towers ranges between 40 and $140 \mathrm{~m}$ and, as for steel towers, they are usually

\footnotetext{
* Corresponding author at: Structural Mechanics Department, Civil Engineering School (Barcelona-Tech) - Technical University of Catalonia. C/ Gran Capitan s/n Ed. C1, Campus Nord, 08034 Barcelona, Spain. Tel.: +34 934016473; fax: +34 934011048.

E-mail addresses: jairoandres@cimne.upc.edu, japaredesl@unal.edu.co (J.A. Paredes).
}

built by means of precast elements assembled in situ, and it has been recognised that well designed reinforced concrete towers have a good behaviour.

The aim of this work is to develop and apply a numerical procedure for the analysis of precast wind turbine reinforced concrete towers subjected to cyclic loads. An increasing monotonic load with unloading and reloading cycle was applied. This procedure allows: (a) capturing the opening, closing and reopening of cracks produced by cyclic loads, and (b) obtaining the capacity curve for future studies on seismic risk. The wind action, thermal effects, machine vibrations and fatigue phenomenon are out of the scope of this study. This work is based on serial/parallel mixing theory [4], a compression-tension damage model [5] and a constitutive law of the elasto-plasticity. Two numerical tools were developed and used in this procedure: constitutive joint concept and global orientation of the steel bar.

Reinforced concrete has been computed as a composite material by using the serial/parallel mixing theory [4]. The steel reinforcement has been treated as an orthotropic elasto-plastic material. The behavior of concrete has been represented by means of the damage model developed by Faria et al. [5]. The serial/parallel mixing theory, together with the damage model allows analyzing reinforced concrete structures under cyclic loading and also capturing the tension-compression cycles. The 
use of the damage model with the thresholds differentiated in tension and compression allows including the "constitutive joint" concept avoiding thus the use of contact elements or of the re-meshing of the contact area. This fact sets the possibility of establishing a powerful strategy for analyzing this type of structure with a high number of finite elements.

The proposed procedure is implemented in the PLCD finite element code [6] which allows performing nonlinear static and dynamic finite element analyses of composite materials [7-12]. This code works with two and three-dimensional solid geometries as well as with prismatic, reduced to one-dimensional members; it computes the numerical solution with a good numerical precision and a reasonable computational cost [10-12] dealing, at the same time, with kinematics and material nonlinearities. It uses various 3-D constitutive laws to predict the material behaviour (elastic, visco-elastic, damage, damage-plasticity, etc. [13]) with different yield surfaces to control their evolution (von-Mises, Mohr-Coulomb, improved Mohr-Coulomb, Drucker-Prager, etc. [14]). Newmark's method [15] is used to perform the transient analysis (cyclic and dynamic). The main numerical features included in the code to deal with composite materials are: (1) Classical and serial/parallel mixing theory used to describe the behaviour of the composite components [16,17]. (2) Anisotropy mapped space theory which enables the code to consider materials with a high level of anisotropy, without the associated numerical problems $[8,17]$. (3) Fiber-matrix debonding which reduces the composite strength due to the failure of the reinforced-matrix in-
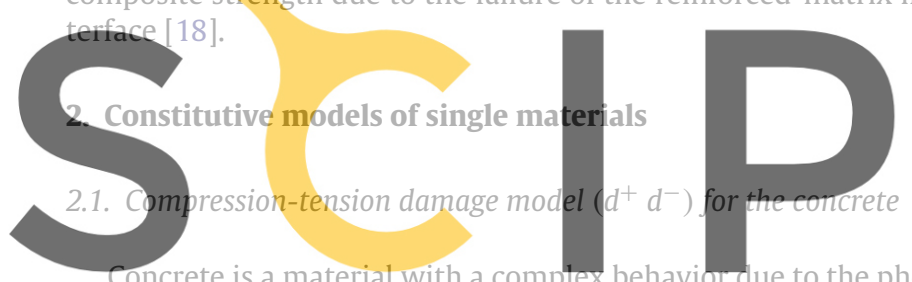

nomena of micro-cracking and sliding between granular parti-

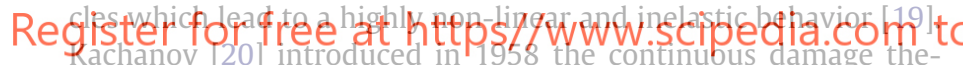

ory and, even if since then several authors have developed different formulations based on this theory [21-26], they have not considered the differentiated damage in tension and compression. In 1998 Faria et al. [5] proposed a formulation with two internal variables, damage to tension $\left(d^{+}\right)$and damage to compression $\left(d^{-}\right)$, in order to cope with the 3D problem of concrete dams subjected to seismic loads. Recently, this formulation has been implemented in the PLCD code $[1,6]$. Although the original model of Faria et al. [5] considers the plastic component in the formulation, the plasticity component of concrete is not taken into account in this paper, in which it is considered that the entire energy dissipation is caused by damage.

A description of this model is given therein. As a starting point, the polar decomposition of the tensor of effective stress, $\bar{\sigma}=\mathbb{C}_{o}$ : $\left(\varepsilon-\varepsilon^{p}\right)=\mathbb{C}_{o}: \varepsilon^{e}$, as a sum of a tensile stress tensor with a compression stress one is required. The tensile stress tensor is defined by $\bar{\sigma}^{+}=\left\langle\bar{\sigma}_{i}\right\rangle p_{i} \otimes p_{i}$ where $\left\langle\bar{\sigma}_{i}\right\rangle$ is Mc Aully's function of the $i$-th principal stress of the effective stress tensor and $p_{i}$ is the corresponding principal direction. The compression stress tensor, $\bar{\sigma}^{-}$, is calculated as $\bar{\sigma}^{-}=\bar{\sigma}-\bar{\sigma}^{+}$.

This model complies with the thermodynamic principles of non-reversible, isothermal and adiabatic processes and defines Helmholtz's free energy as $\psi\left(\varepsilon, \varepsilon^{p}, d^{+}, d^{-}\right)=\left(1-d^{+}\right) \psi_{0}^{+}+(1-$ $\left.d^{-}\right) \psi_{0}^{-}$, where the elastic free energy of tension and compression are defined by $\psi_{0}^{+}\left(\bar{\sigma}\left(\varepsilon, \varepsilon^{p}\right)\right)=\frac{1}{2} \bar{\sigma}^{+}: \mathbb{C}_{0}^{1}: \bar{\sigma}$ and $\psi_{0}^{-}\left(\bar{\sigma}\left(\varepsilon, \varepsilon^{p}\right)\right)=$ $\frac{1}{2} \bar{\sigma}^{-}: \mathbb{C}_{o}^{-1}: \bar{\sigma}$, respectively. Thus, for the elastic case, the equation $\psi_{0}=\psi_{0}^{+}+\psi_{0}^{-}=\frac{1}{2}\left(\bar{\sigma}^{+}+\bar{\sigma}^{-}\right): \mathbb{C}_{0}^{-1}: \bar{\sigma}=\frac{1}{2} \varepsilon: \mathbb{C}_{0}: \varepsilon$ is satisfied.
Due to the quadratic form of the elastic free energies, one perceives that they are positive and, therefore, the energy $\psi$ will be positive as well; moreover, the matrix form of $\mathbb{C}_{o}$ is positive definite and the damage variables $d^{+}$and $d^{-}$take values between 0.0 for an undamaged state and 1.0 for a complete damage state of a material point. This model defines two damage criteria, one for tension $g^{+}\left(\bar{\tau}^{+}, r^{+}\right)=\bar{\tau}^{+}-r^{+} \leq 0$ and another for compression $g^{-}\left(\bar{\tau}^{-}, r^{-}\right)=\bar{\tau}^{-}-r^{-} \leq 0$, where $\bar{\tau}^{+}$and $\bar{\tau}^{-}$are two functions which transform a stress tensor in scalar. The equivalent tension and compression stress functions are

$$
\bar{\tau}^{+}=\left[\bar{\sigma}^{+}: \mathbb{C}_{0}^{-1}: \bar{\sigma}^{+}\right]^{\frac{1}{2}} ; \quad \bar{\tau}^{-}=\left[\sqrt{3}\left(k \bar{\sigma}_{\text {oct }}^{-}+\bar{\tau}_{\text {oct }}^{-}\right)\right]^{\frac{1}{2}}
$$

where $\bar{\sigma}_{\text {oct }}^{-}=\frac{I^{-}}{3} ; \bar{\tau}_{\text {oct }}^{-}=\left[\frac{2}{3} J_{2}\right]^{\frac{1}{2}}$ and $k$ is a parameter which ranges between 1.16 and 1.2 obtained starting from a $1 \mathrm{D}$ and a $2 \mathrm{D}$ compression test; in this case the value 1.2 has been chosen [27]. It defines two elastic behaviour change thresholds $r^{+}$and $r^{-}$in terms of the material characteristics; their initial values are defined by

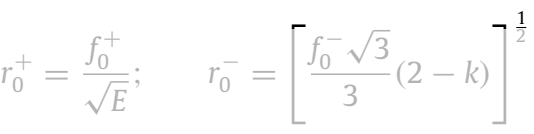

where $f_{0}^{+}$and $f_{0}^{-}$are the ultimate strength of the material in tension and compression, respectively. The internal variables that are considered in the implementation of this model are only the damage ones. The evolution law of the internal damage variables is expressed as

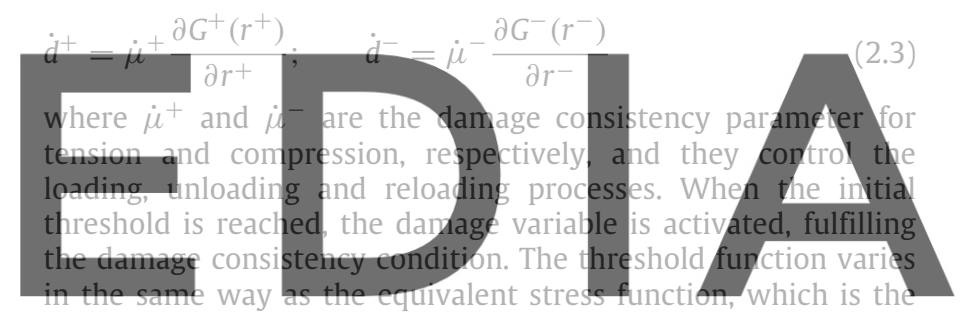

permanency condition on the damage threshold surface

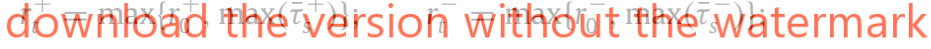 $s \in\{0, t\}$.

By integrating analytically the equation $d^{+}=G^{+}\left(r^{+}\right) \frac{\partial G^{+}}{\partial r^{+}} r^{+}$ tension, the damage function for tension, $d^{+}$, is obtained in the following form:

$$
d^{+}=G^{+}\left(r^{+}\right)=1-\frac{r_{0}^{+}}{r^{+}} \exp \left(A^{+}\left(1-\frac{r^{+}}{r_{0}^{+}}\right)\right) ; \quad \text { if } r^{+} \geq r_{0}^{+} \text {. }
$$

This equation represents the softening of the material subjected to one dimensional tension. The parameter $A^{+}$depends on the mechanical properties of the material and is defined according to the criterion of the objectivity of the mesh. The objectivity is achieved by regularizing the fracture energy $G_{f}$ with the socalled characteristic length $l_{c h}$, which depends on the material's properties and the characteristic dimension of each finite element of mesh

$A^{+}=\left(\frac{G_{f} E}{l_{c h}\left(f_{0}^{+}\right)^{2}}-\frac{1}{2}\right)$.

Starting from equation $\dot{d}^{-}=\dot{G}^{-}\left(r^{-}\right) \frac{\partial G^{-}\left(r^{-}\right)}{\partial r^{-}} \dot{r}^{-}$which describes the evolution of the internal damage variable for compression, the law of evolution of the damage function $d^{-}$is obtained in the following form

$d^{-}=G^{-}\left(r^{-}\right)=1-\frac{r_{0}^{-}}{r^{-}}\left(1-r^{-}\right)-A^{-} \exp \left(B^{-}\left(1-\frac{r^{-}}{r_{0}^{-}}\right)\right)$

if $r^{-} \geq r_{0}^{-}$ 
which is similar to that derived by Mazars and Pijaudier-Cabot in 1989 [28]. The parameters $A^{-}$and $B^{-}$can be defined starting from two points of the stress-strain curve in a 1D compression test; Mazars et al. [28] proposed values $A^{-}=1.4$ and $B^{-}=1.850$. The second law of thermodynamics and the reasoning of Coleman [29], allows obtaining the constitutive law of this damage model

$\left(\sigma-\frac{\partial \psi}{\partial \varepsilon}\right)=0$

$\sigma=\left(1-d^{+}\right) \bar{\sigma}_{0}^{+}+\left(1-d^{-}\right) \bar{\sigma}_{0}^{-}$.

\subsection{Elasto-plastic constitutive model for the steel}

In small deformation problems, the plasticity theory is characterised by assuming the total strain as an additive decomposition of the elastic and plastic components $\varepsilon=\varepsilon^{e}+\varepsilon^{p}$. Because the plastic strains are irreversible, the energetic processes that occur are dissipative and path dependent. The stress-strain relation is given by

$$
\sigma=\mathbb{C}: \varepsilon^{e}=\mathbb{C}:\left(\varepsilon-\varepsilon^{p}\right)
$$

where, $\sigma$ is the second order Cauchy's stress tensor and $\mathbb{C}$ is the fourth order elasticity tensor. According to the plasticity theory, based on the continutum-solid mechanics which describes the behaviour of the ideal solid at macroscopic level, the elastic zone, linear or non-linear, is delimited by a yield function while the elastoplastic zone is described by a non-proportional stress-strain relationship. In this zone, the relatio

and strain rates could be positive $\mathrm{z}$

on the elastoplastic behaviour whic

plasticity or softening. This respond

elastic zone is described by Hooke's I

the elastic and elastoplastic zones

the behaviour in the elastoplastic zone
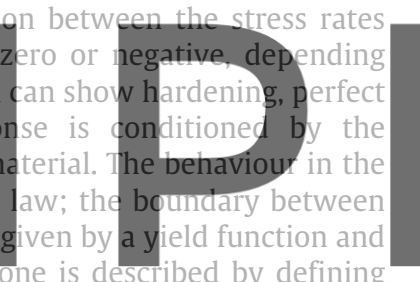

(i) the decomposition of the total strain into its elastic and plastic



of the stress tensor which will be referred to as the plastic yield function

$g(\sigma ; q)=0$

where $\sigma$ is Cauchy's stress tensor and $q$ is a set of internal variables. The plastic yield function in the tension space is a surface that envelops the elastic zone which could expand or contract depending on the hardening or softening behaviour. In order to establish differences between of the plasticity theories, the decomposition of the total strain rate has been traditionally used as a criterion. The Levi-Mises theory admits that the total strain rate is equal to plastic strain rate $\dot{\varepsilon}=\dot{\varepsilon}^{p} \Rightarrow \dot{\varepsilon}^{e}=0$, while the Prandtl-Reus theory defines that total strain rate is composed by the addition of the elastic strain rate with plastic strain rate $\dot{\varepsilon}=\dot{\varepsilon}^{e}+\dot{\varepsilon}^{p}$; thereby the stress-strain rates are related by

$\dot{\sigma}=\mathbb{C}_{t}: \dot{\varepsilon}=\mathbb{C}_{t}:\left(\dot{\varepsilon}^{e}+\dot{\varepsilon}^{p}\right)$

where $\mathbb{C}_{t}$ is the fourth order elastoplastic tangent tensor. In small strains, the classic plasticity theory admits the Prandtl-Reus hypothesis as valid in order to decompose the total strain. Thereby, the plastic strain represents the fundamental internal variable and its evolution is defined by the plastic flow law

$\dot{\varepsilon}^{p}=\dot{\lambda} \frac{\partial G(\sigma ; q)}{\partial \sigma}$

where $G(\sigma ; q)$ is the plastic flow potential and $\dot{\lambda}$ is a non-negative scalar denominated as the plastic consistency parameter. When the plastic flow potential is considered to be equal to the plastic yield function, then it is the plastic associated flow law.
Table 1

Characteristics of the constitutive model for the steel bars.

\begin{tabular}{ll}
\hline Characteristics & Equation \\
\hline von Mises plastic yield function & $g\left(J_{2} ; \tau_{\text {oct }}^{\max }\right)=\frac{1}{2} s: s-\left[\tau_{\text {oct }}^{\max }\right]^{2}=0$ \\
$\begin{array}{l}\text { Plastic flow potential and plastic flow } \\
\text { rule }\end{array}$ & $G\left(J_{2} ; \tau_{\text {oct }}^{\max }\right)=g\left(J_{2} ; \tau_{\text {oct }}^{\max }\right)$ \\
Plastic flow rule & $\dot{\varepsilon}^{p}=\dot{\lambda} \frac{\partial\left(J_{2} ; \tau_{\text {oct }}^{\max }\right)}{\partial J_{2}}=\dot{\lambda} s$ \\
Plastic consistency condition of Prager & $\dot{g}\left(J_{2} ; \tau_{\text {oct }}^{\max }\right)=s: \dot{s}=0$ \\
& $\dot{\lambda}=\sqrt{\frac{\dot{j}_{2}^{\prime}}{J_{2}} ; \dot{J}_{2}^{\prime}=\frac{1}{2}\left(e^{p}: e^{p}\right)}$ \\
$\begin{array}{l}\text { Plastic consistency parameter } \\
\text { Fourth order elastoplastic tangent } \\
\text { tensor }\end{array}$ & $\mathbb{C}_{t}=\mathbb{C}-\frac{\mathbb{C}: s \otimes s: \mathbb{C}}{s: \mathbb{C}: s}$ \\
\hline
\end{tabular}

$G(\sigma ; q) \equiv g(\sigma ; q)$.

The Kuhn-Tucker equations, $\dot{\lambda}=0 ; g(\sigma ; q) \leq 0$ and $\dot{\lambda} g(\sigma ; q)$ $=0$, allow simultaneous satisfying of both the plastic consistency condition of Prager, $\dot{g}(\sigma ; q)=0$, and the loading/unloading condition. Each steel bar material is represented by an associated elastoplastic constitutive law. The von Misses yield function (Eq. (2.11)) bounds the elastic domain; for the plastic domain, an associated flow rule (Eq. (2.14)) is used according to Prandtl-Reus hypothesis [19]. A perfect elastoplastic behaviour of the steel is considered in this work, without internal variables for hardening/softening effects [30]. The characteristics of the constitutive model for the steel bars are defined in Table 1.

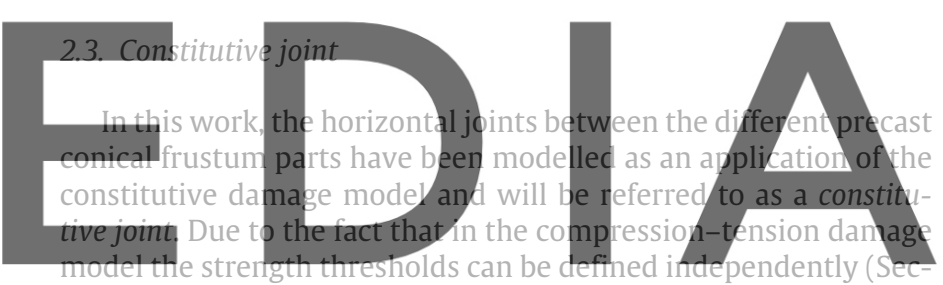

tion 2.1), it is possible to decrease the tensile strength of the con-

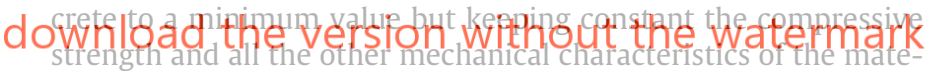

rial. This modified material is assigned to the elements belonging to the joints between the precast members. Thus, when the structure has tension force in the joint planes, the reaction force will be negligible and, conversely, when the forces are compressive, the structural response takes into account the compressive capacity of the concrete. This procedure, which is based on constitutive laws, avoids the use of contact finite element and re-meshing techniques, simplifying thus the numerical solution.

\section{The serial/parallel mixing theory}

Usually, reinforced concrete has three perpendicular bars in each analysis point, and therefore powerful mixing theory is necessary. This mixing theory should permit modelling the reinforced concrete like a composite material. In this case, reinforced concrete is modelled by using the serial/parallel mixing theory [4].

3.1. Definition of the serial/parallel components of the strain and stress tensors

Only two composite components will be included in the serial/parallel mixing theory: fiber (steel bars) and the matrix; the direction of the fiber is considered in parallel while the other one is the serial. In order to take into account this dual condition, it is necessary to subdivide the strain and stress tensors of the composite constituents in their serial and parallel directions. If $e_{1}$ is the direction vector corresponding to the parallel direction of the fiber, the parallel projector tensor can be defined as the dyadic 
product $N_{P}=e_{1} \otimes e_{1}$ and the fourth order parallel projector tensor is $P_{P}=N_{P} \otimes N_{P}$. The serial projector tensor can be evaluated as the complement of the parallel tensor $P_{S}=I-N_{P}$. The strain tensor can be split in its serial and parallel components

$\varepsilon=\varepsilon_{P}+\varepsilon_{S} ; \quad \varepsilon_{P}=P_{P}: \varepsilon \mathrm{y} \varepsilon_{S}=P_{S}: \varepsilon$.

The stress tensor can be subdivided in a similar way

$\sigma=\sigma_{P}+\sigma_{S} ; \quad \sigma_{P}=P_{P}: \sigma \mathrm{y} \sigma_{S}=P_{S}: \sigma$

\subsection{Hypotheses of the numerical model}

The numerical model developed to obtain the stress-strain relationship of the composite starting from the serial/parallel behaviour of its components is based on the following hypotheses: (1) The constituent materials undergo the same strain in the parallel direction (iso-strain condition). (2) The constituent materials have the same stress components in the serial direction (iso-stress condition). (3) The contribution of the components to the response of the composite is directly proportional to its volumetric participation in the composite. (4) A homogeneous distribution of the different components of the composite is considered. (5) The component materials are perfectly bonded to each other.

Constitutive equations of each component material

The behaviour of each component of the composite is described by its own constitutive equation. In this case, the damage constitutive law of the concrete is that given in Section 2.1 and the steel inforcement is represented by th given in Section 2.2. In the specific case damage constitutive law, the relation sh the strains of the material can be written as $\left.d^{-}\right)^{k} \mathbb{C}:\left({ }^{k} \varepsilon\right)+\left(1-d^{+}\right)$
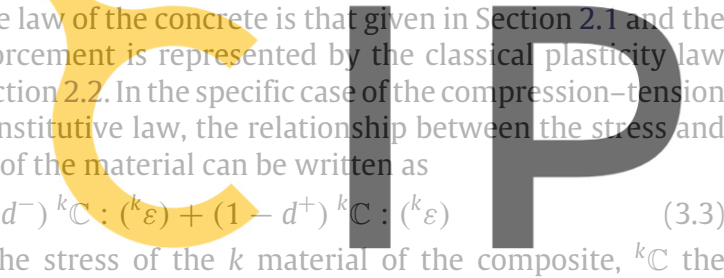
being ${ }^{k} \sigma$ the stress of the $k$ material of the composite, ${ }^{k} \mathbb{C}$ the

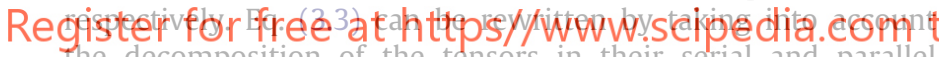
the decomposition of the tensors in their serial and paralle components

$\left[\begin{array}{l}{ }^{k} \sigma_{P} \\ { }^{k} \sigma_{S}\end{array}\right]=\left[\begin{array}{ll}{ }^{k} \mathbb{C}_{P P} & { }^{k} \mathbb{C}_{P S} \\ { }^{k} \mathbb{C}_{S P} & { }^{k} \mathbb{C}_{S S}\end{array}\right]:\left[\begin{array}{l}{ }^{k} \varepsilon_{P} \\ { }^{k} \varepsilon_{S}\end{array}\right]$

where

${ }^{k} \mathbb{C}_{P P}=P_{P}:{ }^{k} \mathbb{C}: P_{P} ; \quad{ }^{k} \mathbb{C}_{P S}=P_{P}:{ }^{k} \mathbb{C}: P_{S} ;$

${ }^{k} \mathbb{C}_{S P}=P_{S}:{ }^{k} \mathbb{C}: P_{P} ; \quad{ }^{k} \mathbb{C}_{S S}=P_{S}:{ }^{k} \mathbb{C}: P_{S}$.

\subsection{Equilibrium and compatibility equations}

The equations defining the stress equilibrium and establishing the strain compatibility of the composite components are obtained starting from the assumptions outlined above. The serial/parallel mixing theory has been formulated for composites with only two components: fiber (steel bar) and matrix. With this approach, the relationship between the two materials in the parallel and serial directions are

Parallel behaviour: ${ }^{c} \varepsilon_{P}={ }^{m} \varepsilon_{P}={ }^{f} \varepsilon_{P}$;

${ }^{c} \sigma_{P}={ }^{m} k^{m} \sigma_{P}+{ }^{f} k^{f} \sigma_{P}$

Serial behaviour: ${ }^{c} \varepsilon_{S}={ }^{m} k^{m} \varepsilon_{S}+{ }^{f} k^{f} \varepsilon_{S}$;

${ }^{c} \sigma_{S}={ }^{m} \sigma_{S}={ }^{f} \sigma_{S}$

where the super indices $c, m$ and $f$ stand for the material: ${ }^{i} k$ denotes the volumetric participation of the material in the composite.

\subsection{Numerical implementation of the serial/parallel mixing theory}

Considering the mixing theory as a manager of the constitutive equations, its implementation in a finite element code is made at the constitutive level, that is, in the part of the code which, starting from the deformation in a Gauss integration point, calculates the corresponding stress. Then, being the strain of the composite ${ }^{c} \varepsilon$ at time instant $t+\Delta t$ entered into the algorithm, this calculates the stress-strain state of each compounding material which meets the equations of equilibrium and compatibility and delivers the stress ${ }^{c} \sigma$ in the composite. The first operation performed by the algorithm is to separate the strain tensor into its serial and parallel parts, calculating the strains in the fiber and matrix compounding materials. In the next step, the parallel part of the strain tensor is, according to Eq. (3.6), the same for both compounding materials. On the other hand, the serial component requires a first prediction of the expected strains in any of the components. If this prediction is made for the matrix material, the increase of the expected strain in the current load step can be expressed as

\section{$\left[{ }^{m} \Delta \varepsilon_{S}\right]^{0}=\mathbb{A}:\left[{ }^{f} \mathbb{C}_{S S}:{ }^{c} \Delta \varepsilon_{S}+{ }^{f} k\left({ }^{f} \mathbb{C}_{S S}-{ }^{m} \mathbb{C}_{S P}\right){ }^{c} \Delta \varepsilon_{P}\right]$} where $\mathbb{A}=\left({ }^{m} k{ }^{f} \mathbb{C}_{S S}+{ }^{f} k^{m} \mathbb{C}_{S S}\right){ }^{-1}$ and ${ }^{c} \Delta \varepsilon_{S}={ }^{t+\Delta t}\left[{ }^{c} \varepsilon_{S}\right]-{ }^{t}\left[{ }^{c} \varepsilon_{S}\right]$. With this first approximation of the serial strain in the matrix, the strain tensor in the fiber (steel bar) can be calculated using the equilibrium condition (Eq. (3.7)).

${ }^{t+\Delta t}\left[{ }^{f} \varepsilon_{S}\right]^{0}=\frac{1}{f k}^{t+\Delta t}\left[{ }^{c} \varepsilon_{S}\right]-\frac{}{f k}^{t}{ }^{t+\Delta t}\left[{ }^{m} \varepsilon_{S}\right]$.

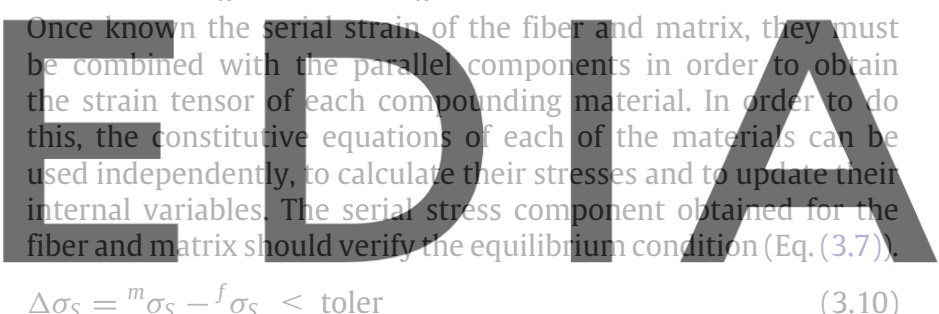

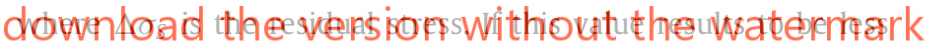

than the tolerance, the initial serial strain prediction for the matrix, and also the obtained stresses, will prove to be correct. On the other hand, if Eq. (3.10) is not verified, the initial prediction of the strains should be corrected. This correction is performed by using a Newton-Raphson scheme, in which the Jacobian of the residual stress has to be obtained. In this case, the equation of the Jacobian is

$\mathbb{J}=\left.\frac{\partial \Delta \sigma_{S}}{\partial^{m} \varepsilon_{S}}\right|_{m_{\varepsilon_{S}=\left[{ }^{m} \varepsilon_{S}\right]^{n}}}=\left[{ }^{m} \mathbb{C}_{S S}\right]^{n}+\frac{{ }^{m} k}{{ }^{f} k}\left[^{f} \mathbb{C}_{S S}\right]^{n}$

with $n$ the number of the last iteration which has been performed. Once the Jacobian has been obtained, the correction of the predictor of the serial strain tensor of the matrix is

$\left[{ }^{m} \varepsilon_{S}\right]^{n+1}=\left[{ }^{m} \varepsilon_{S}\right]^{n}-\mathbb{J}^{-1}:\left[\Delta \sigma_{S}\right]^{n}$.

To achieve a quadratic convergence using the serial/parallel mixing theory, the Jacobian has to be obtained using the tangent constitutive tensors of the steel bar and of the matrix. According to the constitutive equation which is used for each of these materials, an analytical expression providing the tangent constitutive tensors could be not available. To overcome this difficulty, and aiming to obtain a robust algorithm, a numerical derivation using the perturbation theory has been developed. The flow chart of Fig. 1 shows how the algorithm based on the serial/parallel mixing theory works.

\section{Global orientation of the steel bars}

In the of serial/parallel mixing theory, the steel bar is oriented according to Euler's angles $\phi^{\text {mat }}, \theta, \psi$ in a 3-1-3 rotation sequence 

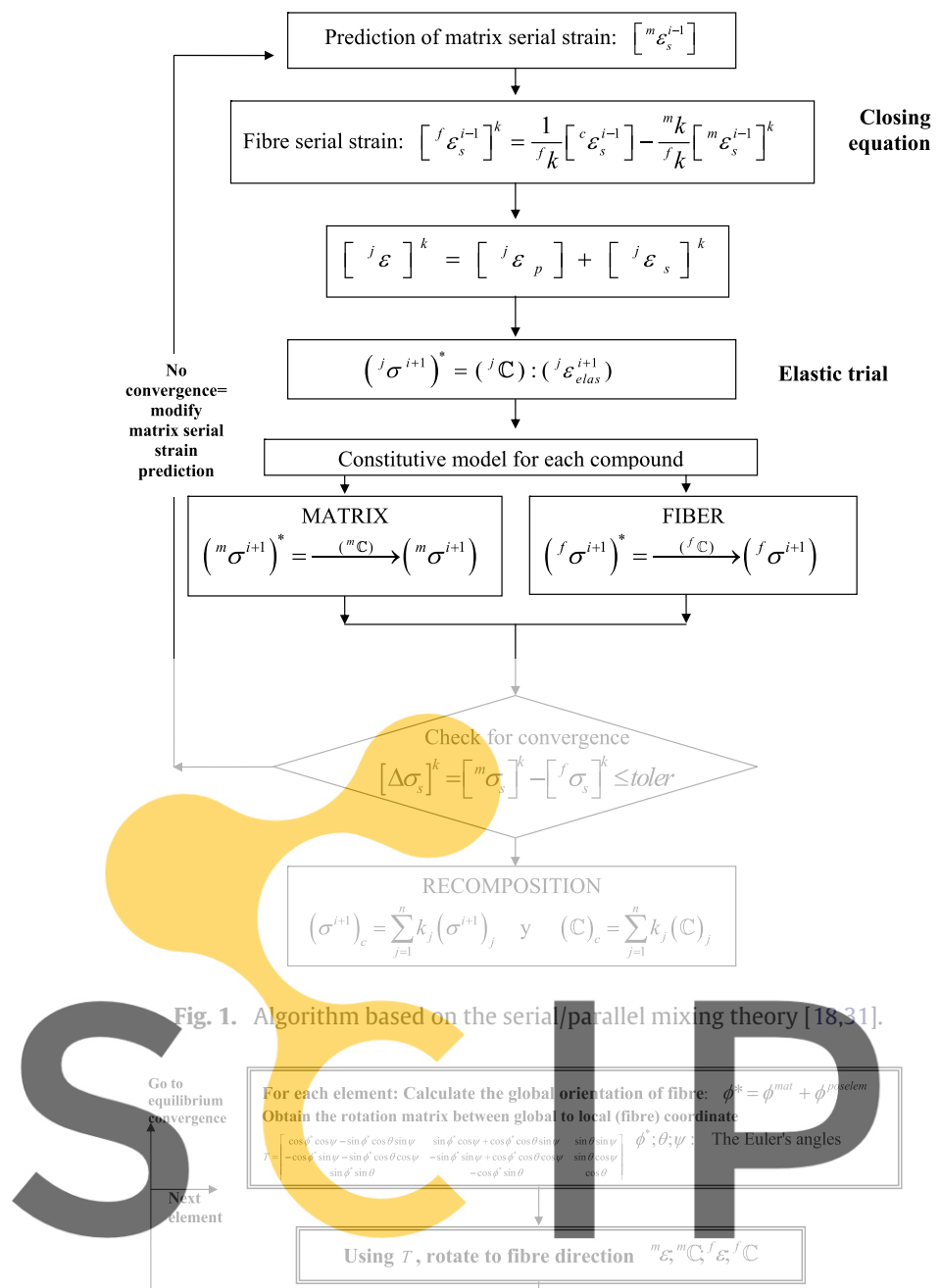

Register for free atedattposfilwwaw: \$cipedia.com to

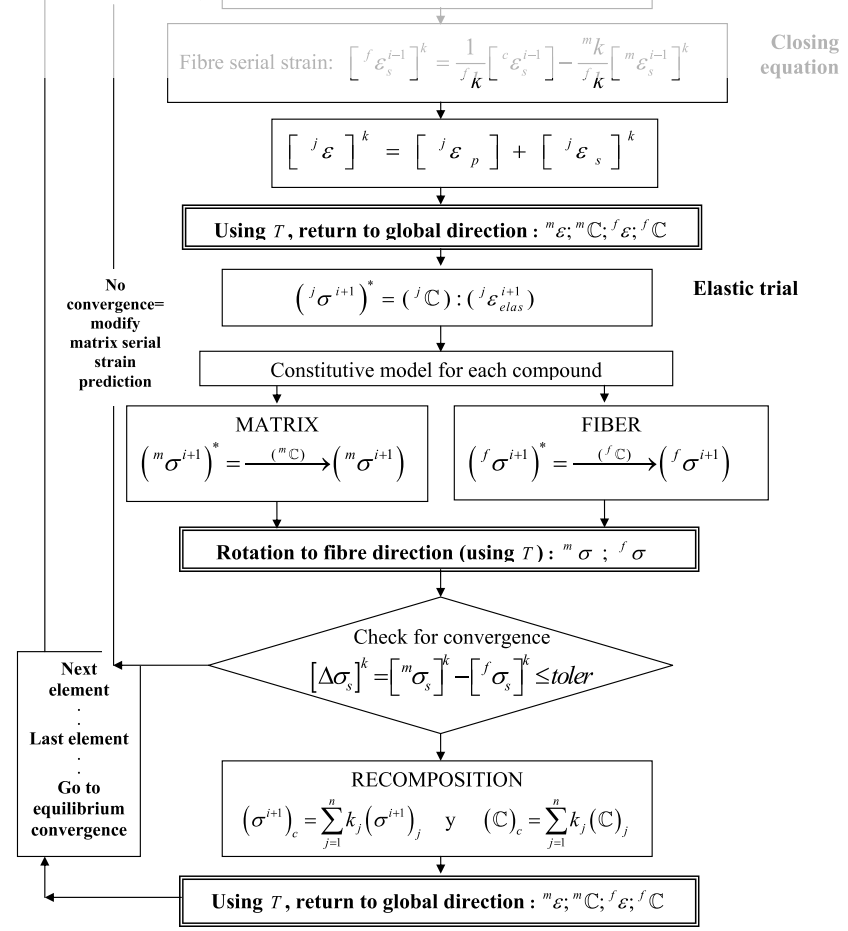

Fig. 2. Algorithm based on the serial/parallel mixing theory with orientation of the fiber (steel bar) in each element (modified from [18,31]).

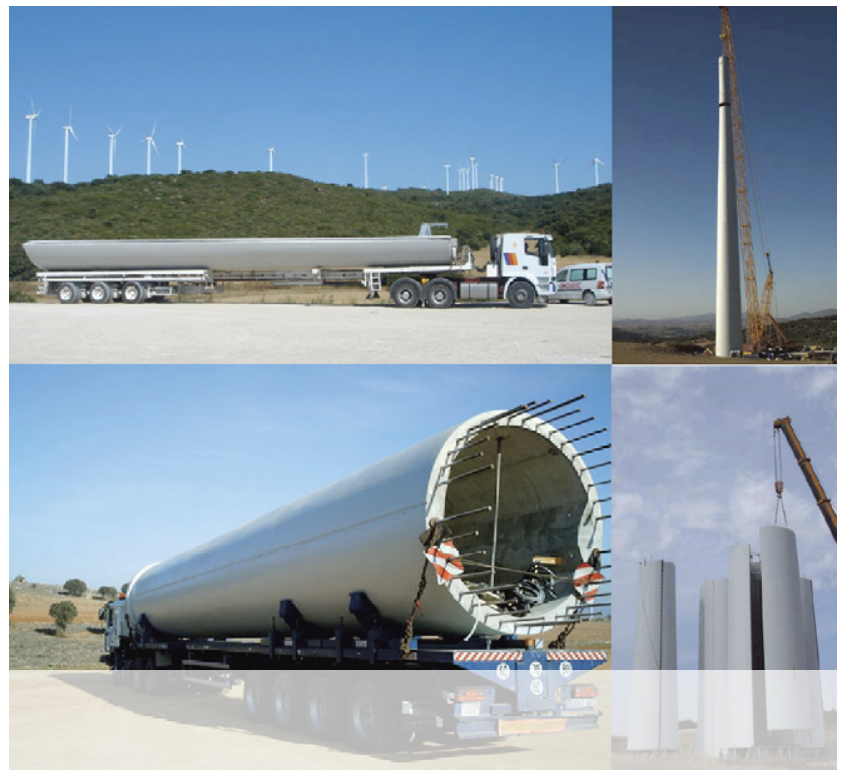

Fig. 3. Reinforced concrete tower with a height of $100 \mathrm{~m}$. Source: [33].

[32], taking advantage of the fact that the first rotation is made in the original $z$-axis and that the vertical axis of the structure coincides with the $z$ axis. The orientation of the steel bars in each

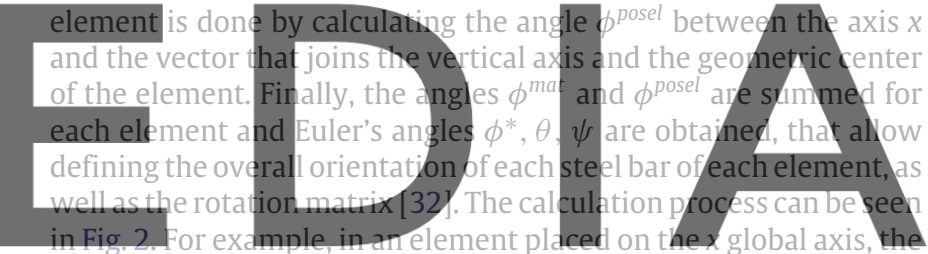
tangential steel bar will be oriented according to $0^{\circ}, 90^{\circ}, 0^{\circ}$ Euler's angles; while for an element located on an axis $x^{\prime}$ at a $40^{\circ}$ angle

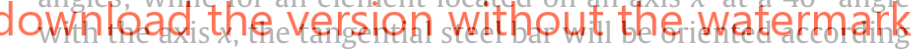
to Euler's angles, which are $40^{\circ}, 90^{\circ}, 0^{\circ}$. The stiffness matrix of each element is calculated considering the overall orientation of the steel bar.

\section{Anisotropy of the composites}

Even though the simple materials are considered isotropic, the serial/parallel mixing theory allows capturing of the anisotropic behaviour the composites, because the steel bars reinforce the structure according to preferential direction. Thus, the use of a serial/parallel mixing theory can capture the anisotropy as a structural behaviour of the composites. When the simple materials have an anisotropic behaviour, the anisotropy mapped space theory [8] can be used. If the anisotropy mapped space theory would be associated with the serial/parallel mixing theory, the anisotropic behaviour of the composite is as a result of combining the anisotropy of each simple material with the anisotropy of reinforcement orientation.

\section{Numerical example}

\subsection{General description of the structure}

A reinforced concrete tower with a height of $77.4 \mathrm{~m}$, composed by four precast conical frustum members, has been studied. Fig. 3 shows examples of precast parts of this type of structure.

The wall thickness changes between 0.15 and $0.35 \mathrm{~m}$ along the height of the tower (see Fig. 4). Particularly there are three zones: 


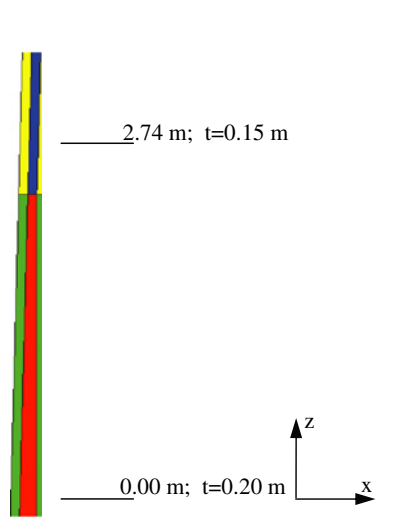

(a) Wall thickness at the basement.

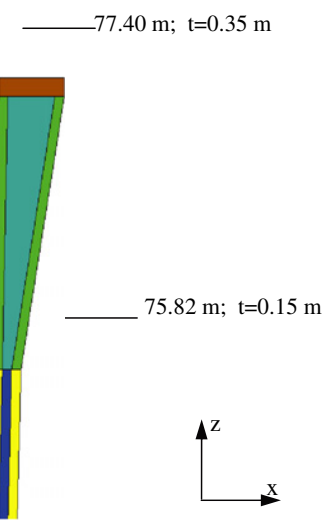

(b) Wall thickness at the top of the tower.

Fig. 4. Wall thickness.
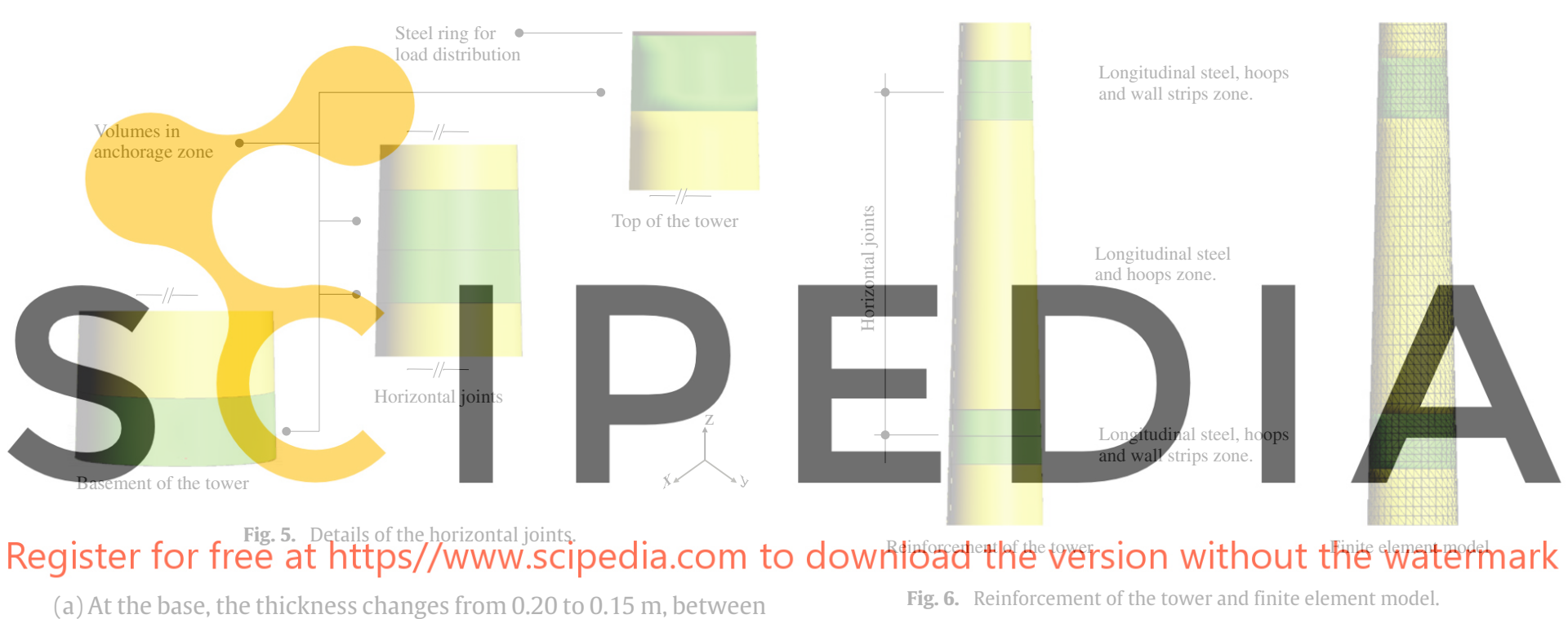

(a) At the base, the thickness changes from 0.20 to $0.15 \mathrm{~m}$, between the levels 0.0 and $2.14 \mathrm{~m}$ (see Fig. 4(a)); (b) between 2.14 and $75.82 \mathrm{~m}$ the thickness is constant having $0.15 \mathrm{~m}$; and (c) at the top it changes from 0.15 to $0.35 \mathrm{~m}$ between the levels 75.82 and $77.40 \mathrm{~m}$ (see Fig. 4(b)). The diameter of the tower at the base is $6.3 \mathrm{~m}$ and at the upper part is $2.4 \mathrm{~m}$.

Horizontal joints. At the levels 20.00, 40.00 and $60.00 \mathrm{~m}$ there are horizontal joints connect the prefabricated parts with vertical steel bolts. In order to represent geometrically these joints a horizontal area common to both the upper and lower volumes is modelled. In addition, volumes covering the length of the anchors to both sides of the horizontal joint are generated (see Fig. 5). In the real geometric design, thickness increase is considered in this area; thus in order to simplify the geometric model, the thickness of the wall in these areas is fixed to $0.15 \mathrm{~m}$.

A horizontal joint connecting the bottom of the tower with the foundation is considered. The thickness of this point of the developed model has the actual thickness of the structure (see Fig. 5). At the top of the tower, volumes are considered that represent the areas where are the anchors connect the wind turbine with the tower. Additionally, a ring-shaped volume that represents the base of the wind turbine was placed (see Fig. 5).

Structural reinforcement of the tower. The reinforcement of the tower has longitudinal steel bars, hoops and wall strips. The anchors are oriented in the longitudinal direction. In the part of the tower with anchors, the design criteria require longitudinal steel bars, hoops and wall strips. In the central part of each section of

the tower, the current reinforcement consists of longitudinal steel bars and hoops (see Fig. 6).

\subsection{Numerical model of the structure}

A 3D numerical model has been developed with 104,976 tetrahedral elements (see Fig. 6). The 3D analysis implies that the different families of steel bars change their orientation depending on the overall position of each finite element. Therefore, an algorithm allowing calculating the actual (global) direction of each steel bar for each finite element was implemented (see Section 4). The analysis of the studied reinforced concrete tower was made for two different cases: Case A, considering perfect connections for the structure, without considering constitutive joint; and Case B, considering constitutive joints in the horizontal planes. Six composites are used in Case A which can be seen in Fig. 7, while for the Case B the seven composites of Fig. 8 are used. MC7 is the material of the constitutive joint.

\subsection{Single materials and composites assigned to different structural parts}

Three simple materials are used in the finite element model: concrete, modified concrete for the constitutive joints and steel. Table 2 shows the main mechanical properties. The parameters $A^{-}$ and $B^{-}$of the concrete are obtained by calculating the compression 


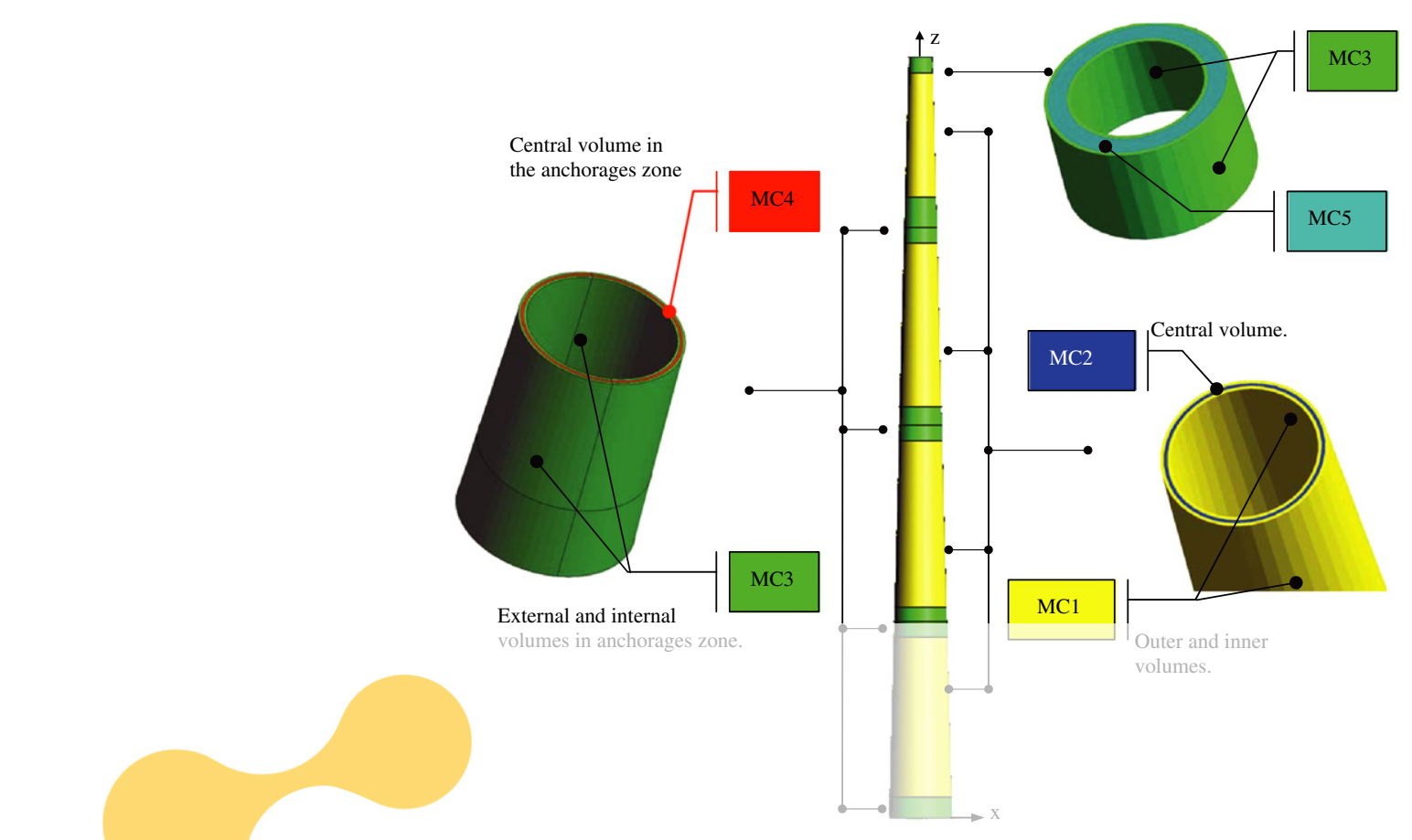

Fig. 7. Assignment of the materials. Case A: structural model without constitutive joint.
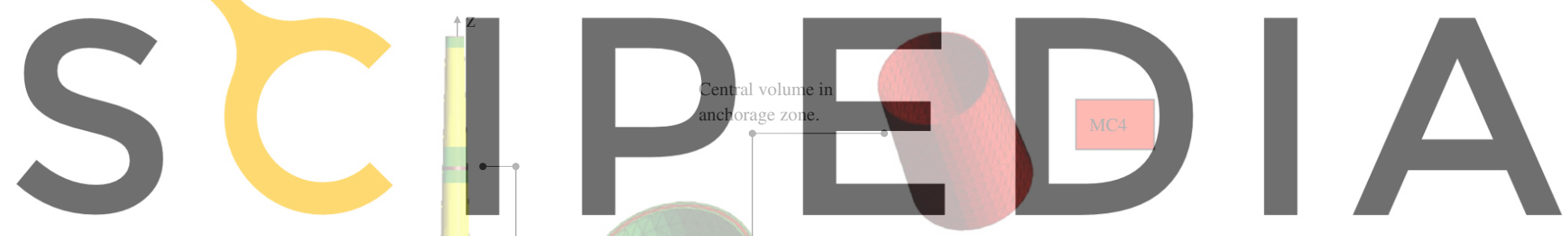

Register for free at https//www.scipedia.com to download the bersign without the watermark
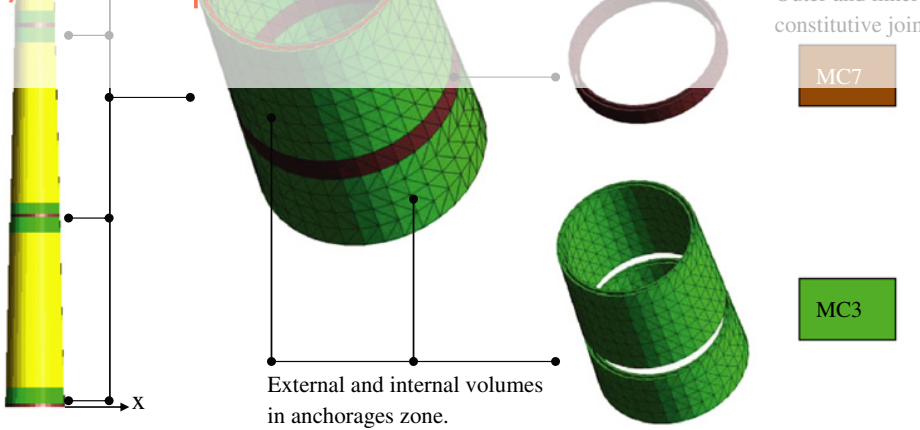

Fig. 8. Assignment of the materials. Case B: structural model with constitutive joint.

Table 2

Mechanical properties of the individual materials.

\begin{tabular}{llllll}
\hline Material type & Concrete & Concrete constitutive joint & Steel & & \\
\hline Material name & MS1 & MS5 & MS2 & MS3 & MS4 \\
$\phi^{\text {mat }}$ & 0 & 0 & 0 & 0 & 0 \\
$\theta$ & 0 & 0 & 90 & 90 & 0 \\
$\psi$ & 0 & 0 & 91.4 & 0 & 0 \\
Constitutive model & $d^{+} d^{-}$ & $d^{+} d^{-}$ & Elasto-plastic & \\
$E(\mathrm{MPa})$ & $3.7 \cdot 10^{4}$ & $3.7 \cdot 10^{4}$ & $2.1 \cdot 10^{5}$ & \\
$v$ & 0.20 & 0.20 & 0.00 & \\
$\sigma_{C}^{o}(\mathrm{MPa})$ & 30 & 30 & 500 & \\
$\sigma_{C}^{\text {ult }}(\mathrm{MPa})$ & 58 & 58 & 500 & \\
$\sigma^{\circ}(\mathrm{MPa})$ & 4.1 & 0.05 & 500 & \\
$G_{C}[\mathrm{kPa} \mathrm{m}]$ & 100 & 100 & 2000 & \\
$G_{T}[\mathrm{kPa} \mathrm{m}]$ & 0.68 & 0.68 & 2000 & \\
\hline
\end{tabular}


Table 3

Volumetric composition of the composite materials (\%).

\begin{tabular}{lrllrr}
\hline \multirow{2}{*}{ Composites } & \multicolumn{2}{l}{ Single materials } \\
\cline { 2 - 6 } & \multicolumn{1}{c}{ MS1 } & MS2 & MS3 & \multicolumn{1}{c}{ MS4 } & \multicolumn{1}{c}{ MS5 } \\
\hline MC1 & 96.80 & 2.400 & 0.800 & 0.000 & 0.000 \\
MC2 & 100.000 & 0.000 & 0.000 & 0.000 & 0.000 \\
MC3 & 95.883 & 2.670 & 0.217 & 1.230 & 0.000 \\
MC4 & 97.030 & 2.850 & 0.000 & 0.120 & 0.000 \\
MC5 & 96.750 & 1.840 & 0.706 & 0.706 & 0.000 \\
MC6 & 0.000 & 0.000 & 0.000 & 100.000 & 0.000 \\
MC7 & 0.000 & 0.000 & 0.000 & 0.000 & 100.000 \\
\hline
\end{tabular}

damage variable $d_{i}^{-}=1-\sigma_{i} / E \varepsilon_{i}$ in two points of a simple compression stress-strain curve. The threshold function $r_{i}$ is calculated using the elastic strain $\bar{\sigma}^{-}=E \varepsilon_{i}$ and knowing the initial threshold. These values are replaced in Eq. (2.7) and a system of two equations with the unknowns $A^{-}$and $B^{-}$is obtained and solved by an iterative process to calculate $A^{-}$and, then, $B^{-}$. Fig. 9 outlines this numerical process. For the structure analyzed in this paper, the values $A^{-}=3.7627$ and $B^{-}=0.7097$ were used. Five simple materials are defined (MS1-MS5); Euler's angles $\phi^{\text {mat }}, \theta, \psi$ defining the orientation of each single material are shown in Table 2 . The volumetric composition of the distinct composite materials is shown in Table 3 while their spatial distribution is shown for Case A and Case B in Figs. 7 and 8, respectively.

\subsection{Applied loads}

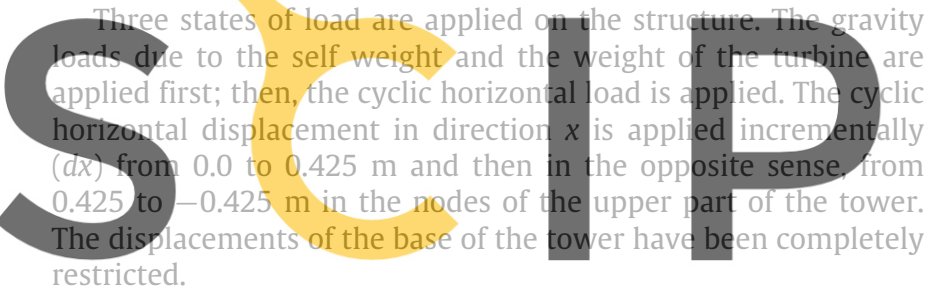

\section{Registempulfor free at https//www.scipedia.com to \\ Fig. 10 shows the force-displacement curves for the cyclic loads} applied on the structure, in which it can be observed that the overall stiffness of the structure is not affected by the use of the constitutive joint. In general, the strength in Case B is slightly lower when compared with that of Case A. However, the use of this numerical tool can capture the damage levels in the structural areas of the connections between the precast members, that is, material MC4, Figs. 7 and 8 show the volumes with material MC4 corresponding to the anchorage zones, while Figs. 13 and 14 show the tension damage evolution in the same zones.

In Case B (with constitutive joints), it can be seen that at the end of the unload stage there is a permanent deformation. This is due to the fact that the longitudinal stresses are larger that the stress yield in the longitudinal fibre of the MC4 composite. Thus, we can see the capability of the constitutive joint in modelling this problem. When the loading direction changes, the elements previously subjected to tensile stresses are compressed and vice versa. However, the overall structural response of the tower does not change as it can be see in Fig. 10, excepting in the part of the curve (Case B) in which there is permanent deformation. This fact confirms that the elements with tensile damage have not lost their capacity to withstand the subsequent compression considering the contact effect. In the unloading cycle, it can be seen that in Case A (without constitutive joints) the original overall stiffness of the structure gradually recuperates while lateral displacement tends to the origin. This is due to the fact that the elements in tension area starting gradually to work in compression. In this state of the cycle, these elements do not show compression damage.

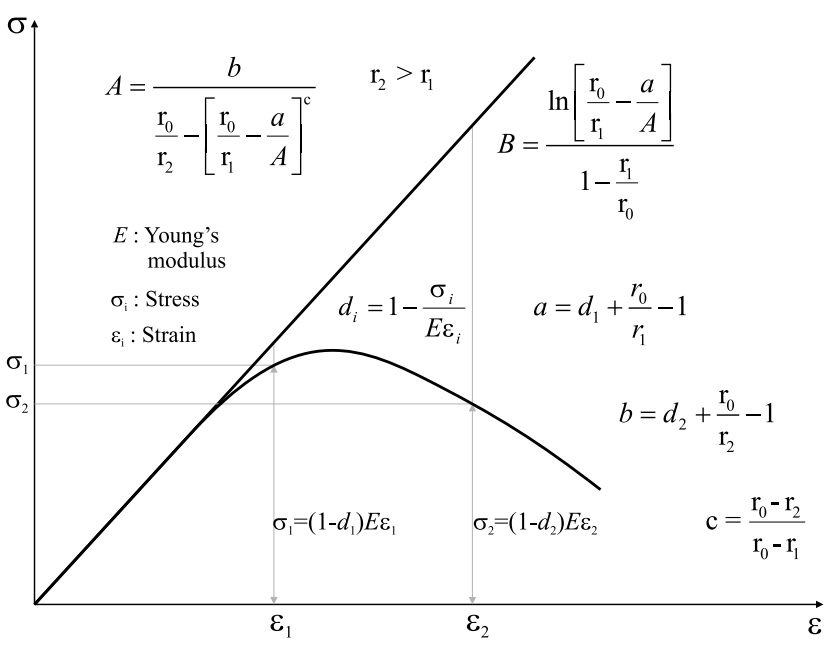

Fig. 9. Calculation scheme for $A^{-}$y $B^{-}$.
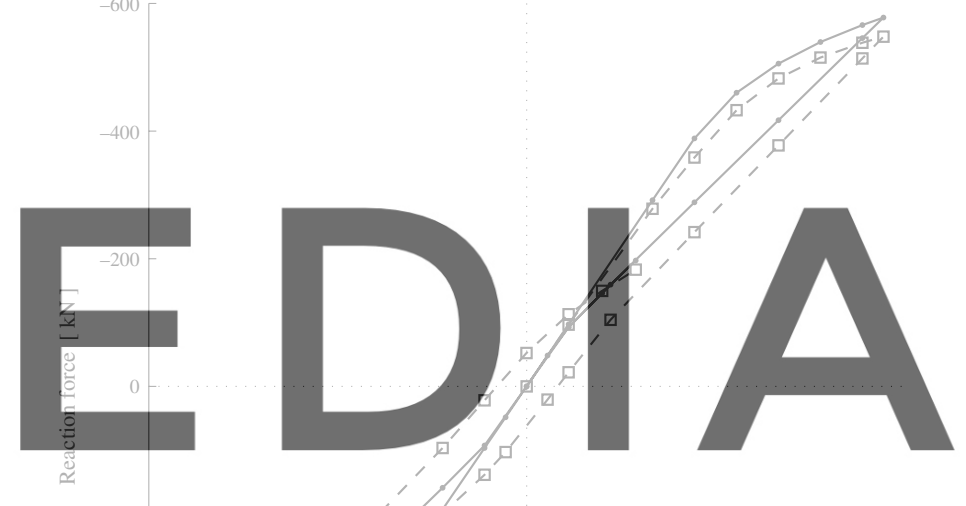

download the vérsition without the watermark

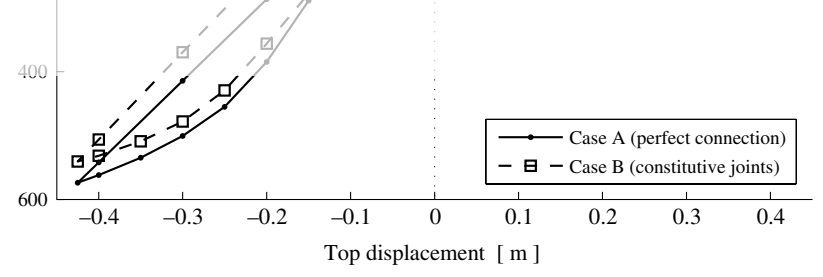

Fig. 10. Load-displacement curves for the Cases A and B.

The evolution of damage in function of the load cycle is shown in items (a)-(d) of the captions of Figs. 11-14. For the load stage, the damage level when the non-lineal behaviour begins can be seen in the items (a), while the damage level in the maximum applied load is shown in items (b). For the opposite sense load, the damage level evolution is shows in items (c) and (d).

The tensile damage in the matrix of the composite material MC1 starts when the lateral displacement at the top lies between 0.15 and $0.25 \mathrm{~m}$. Comparing the two studied models, results are shown in Figs. 11 and 12, it can be concluded that the matrix of the composite material MC1 shows a higher level of tensile damage in Case A than in Case B, while the matrix of the composite material MC4 (see Figs. 13 and 14) shows a higher level of tensile damage in Case B than in Case A. This is due to the fact that in Case B there is a concentration of tensile stress in the anchorages zone (composite material MC4) due to constitutive joint which is not present in Case A. 

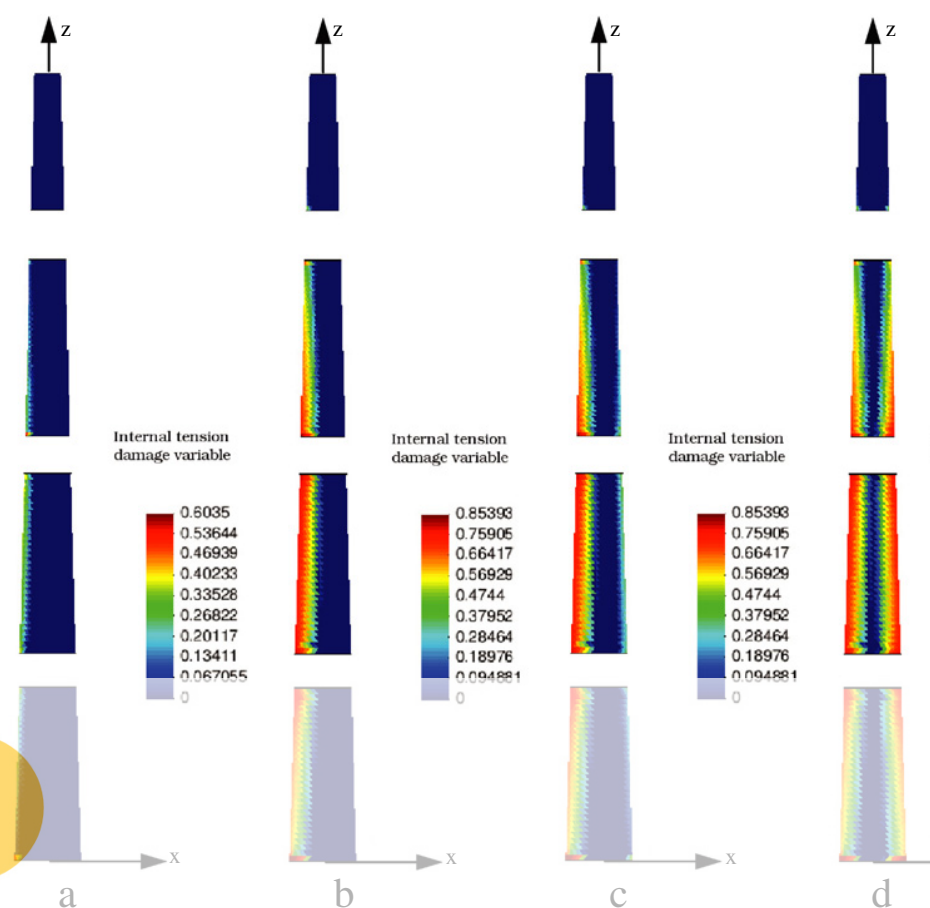

Internal tension
damage variable

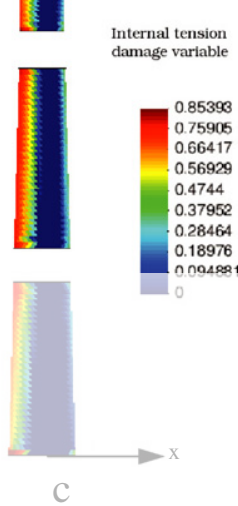

Internal tension

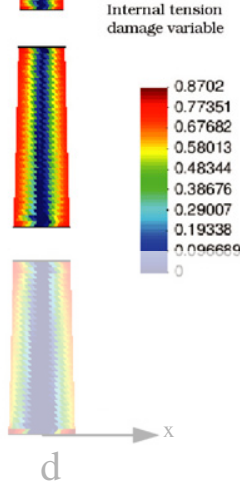

Fig. 11. Damage in the structure model without constitutive joint (material MC1); (a) $d x=0.25 \mathrm{~m}$; (b) $d x=0.425 \mathrm{~m}$; (c) $d x=-0.25 \mathrm{~m}$; (d) $d x=-0.425 \mathrm{~m}$, where $d x$ is the lateral displacement at the top of the tower.
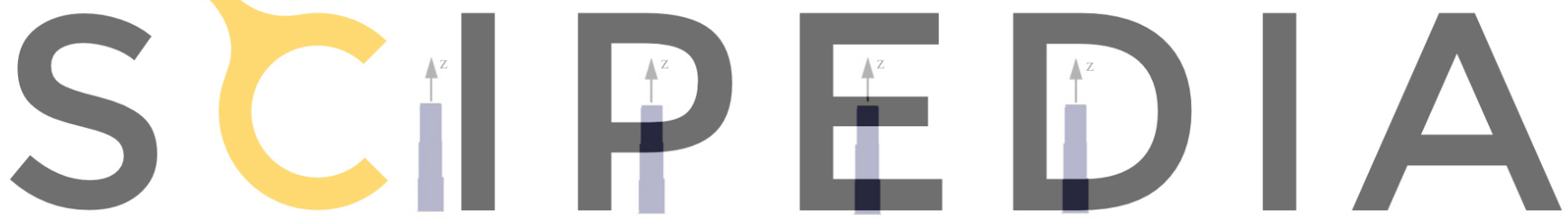

Register for free at https//www.scipedia.com to download the version without the watermark

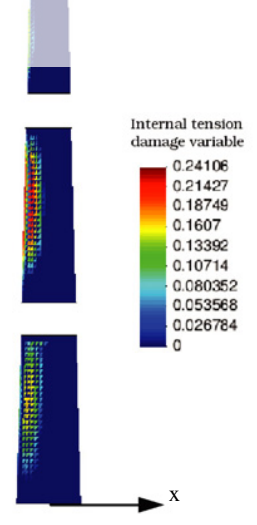

a

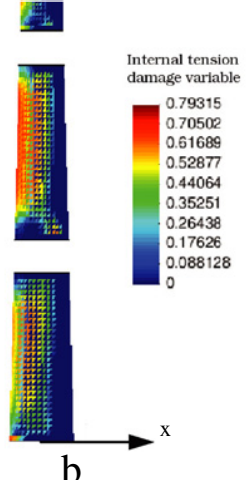

b
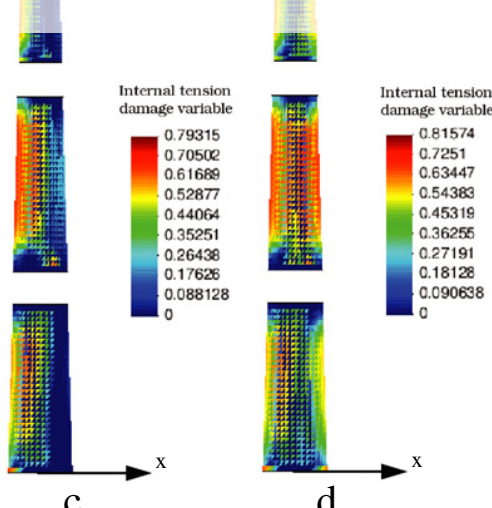

Fig. 12. Damage in the structure model with constitutive joint (material MC1); (a) $d x=0.25 \mathrm{~m}$; (b) $d x=0.425 \mathrm{~m}$; (c) $d x=-0.25 \mathrm{~m}$; (d) $d x=-0.425 \mathrm{~m}$, where $d x$ is the lateral displacement at the top of the tower.

\section{Conclusions}

A procedure for the analysis of wind turbine reinforced concrete towers subjected to cyclic loads was developed and applied. Serial/parallel mixing theory, compression-tension damage model and elasto-plastic constitutive law were applied and two numerical tools were developed: constitutive joint concept and global orientation of the steel bars. The proposed procedure, together with the anisotropy due to the reinforcement orientation, is a powerful tool for modeling structures of the type studied herein, avoiding the use of re-meshing and of joint elements in the areas of connections between precast members.

The algorithm allows establishing the steel bar orientation, locates the steel reinforcement of the structure, optimizing the computational resources and facilitating the use of the serial/parallel mixing theory. It can be observed that in the loading cycle the overall stiffness of the structure is not affected by the use of the constitutive joint, while the damage distribution is different 


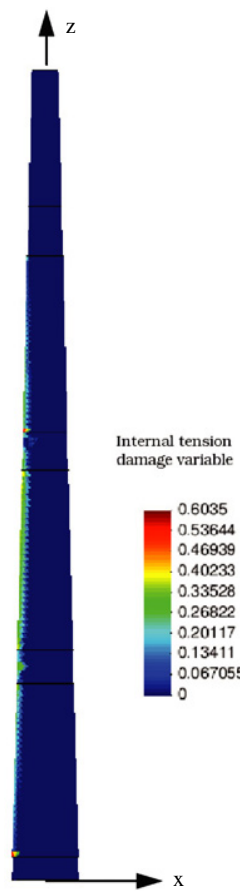

a

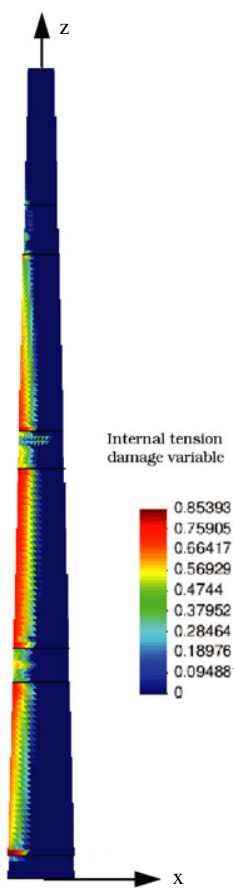

b

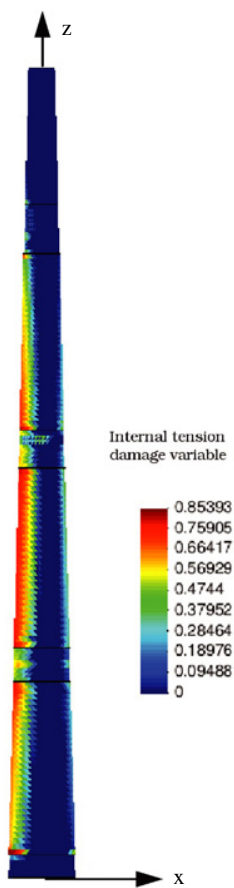

C

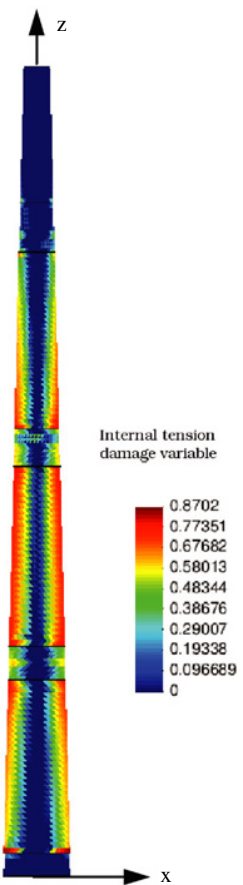

d

Fig. 13. Damage in the structure model without constitutive joint (material MC1 y MC4); (a) $d x=0.25 \mathrm{~m}$; (b) $d x=0.425 \mathrm{~m}$; (c) $d x=-0.25 \mathrm{~m}$; (d) $d x=-0.425 \mathrm{~m}$, where $d x$ is the lateral displacement at the top of the tower.

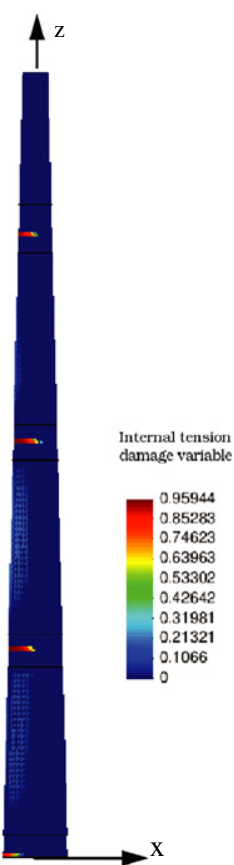

$\mathrm{a}$

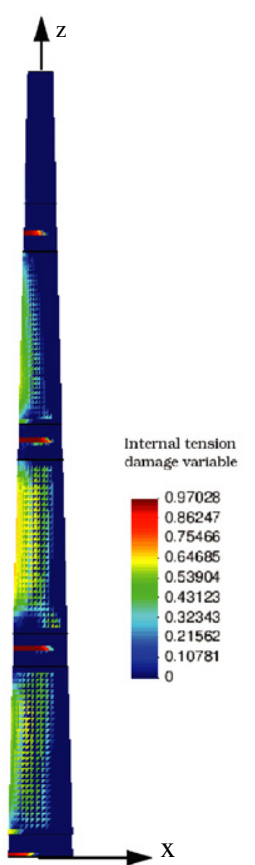

b

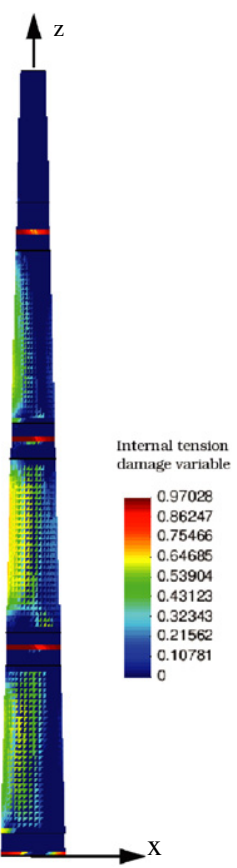

C

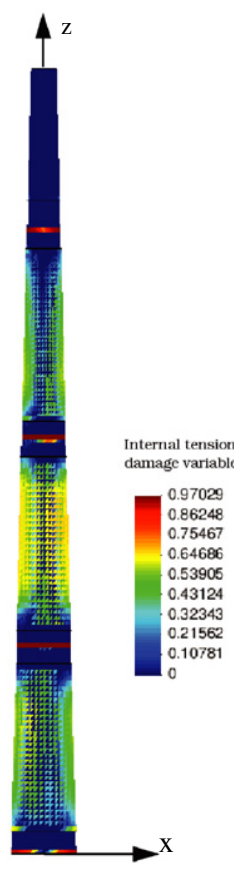

d

Fig. 14. Damage in the structure model with constitutive joint (material MC1 y MC4); (a) $d x=0.25 \mathrm{~m}$; (b) $d x=0.425 \mathrm{~m}$; (c) $d x=-0.25 \mathrm{~m}$; (d) $d x=-0.425 \mathrm{~m}$, where $d x$ is the lateral displacement at the top of the tower.

for each case studied. As a result of this study, the phenomenon of opening, closing and reopening of cracks produced by cyclic loads are obtained. Figs. 11-14 show the damage evolution in the structure. In items (a) it can be seen that damage begins in traction zone (opening of cracks phase); in items (b) bigger damage can be seen in the same zone (opening of cracks phase). When the loading direction changes, the elements previously subjected to tensile stresses are compressed (closing of cracks phase) and vice versa (opening or re-opening of cracks phase), as can be seen in Figs. 1114 , items (c) and (d). As future work, this procedure will be the base of the seismic and dynamic analysis of this type of structure. The study of changes in the frequencies of the structure, caused 
by the evolution of damage in the composite material should be developed. The use of a single yielding surface in the differentiate damage constitutive model is foreseen. The thermomechanical and fatigue analyses are important issues open for future studies.

\section{References}

[1] Barbat A, Paredes JA, Oller S. A new damage model for structures subjected to cyclic loads. In: 9th world congress on computational mechanics and 4th asian pacific congress on computational mechanics Sydney. Centre for Infrastructure Engineering and Safety; 2010. p. 142.

[2] Harte R, Van Zijl. GPAG. structural stability of concrete wind turbines and solar chimney towers exposed to dynamic wind action. J Wind Eng Ind Aerodynam 2007;95:1079-96.

[3] Petcu C, Marí-Bernat A. Concept and design of tall reinforced and prestressed wind towers [Tesina], Barcelona: Universidad Politécnica de Cataluña; 2007.

[4] Rastellini F. Modelización numérica de la no-linealidad constitutiva de laminados compuestos. Ph.D. thesis. Barcelona: Universidad Politécnica de Cataluña; 2006

[5] Faria R, Oliver J, Cervera M. A strain-based plastic viscous-damage model for massive concrete structures. Int J Solids Struct 1998;35:1533-58.

[6] PLCD-Manual. Non-linear thermo mechanic finite element oriented to Ph.D. student education. Code developed at CIMNE. Barcelona; 2008.

[7] Oller S, Barbat AH. Moment-curvature damage model for bridges subjected to seismic loads. Comput Methods Appl Mech Eng 2006;195:4490-511.

[8] Car E, Oller S, Oñate E. A large strain plasticity model for anisotropic materials - composite material application. Int J Plasticity 2001;17:1437-63.

[9] Molina M, Oller S, Barbat AH, Martínez X. Análisis numérico de estructuras de hormigón reforzadas con FRP por medio de la teoría de mezclas serie/paralelo. Revista internacional de Métodos numéricos para cálculo y diseño en ingeniería. 2010. 26. p. 135-55.

[10] Mata P, Oller S, Barbat AH. Static analysis of beam structures under nonlinear geometric and constitutive behavior. Comput Methods Appl Mech Eng 2007; 196:4458-78.

[11] Mata P, Oller S, Barbat AH. Dynamic analysis of beam structures considering geometric and constitutive nonlinearity. Comput Methods Appl Mech Eng 2008; $197: 857-78$.

[12] Mata P, Barbat AH, Oller S. Two-scale approach for the nonlinear dynamic analysis of RC structures with local non-prismatic parts. Eng Struct 2008;30: 3667-80.
[13] Oller S, Oñate E, Oliver J, Lubliner J. Finite element nonlinear analysis of concrete structures using a plastic-damage model. Eng Fracture Mech 1990; $35: 219-31$.

[14] Lubliner J, Oliver J, Oller S, Oñate E. A plastic-damage model for concrete. Int J Solids Struct 1989;25:299-326.

[15] Barbat AH, Oller S, Oñate E, Hanganu A. Viscous damage model for Timoshenko beam structures. Int J Solids Struct 1997;34:3953-76.

[16] Faleiro J, Oller S, Barbat AH. Plastic-damage seismic model for reinforced concrete frames. Comput Struct 2008;86:581-97.

[17] Oller S, Car E, Lubliner J. Definition of a general implicit orthotropic yield criterion. Comp Methods Appl Mech Eng 2003;192:895-912.

[18] Martinez X, Oller S, Rastellini F, Barbat AH. A numerical procedure simulating RC structures reinforced with FRP using the serial/parallel mixing theory. Comput Struct 2008;86:1604-18

[19] Oller S. Modelización numérica de Materiales Friccionales. Barcelona: CIMNE; 1991.

[20] Kachanov LM. Time of rupture process under creep conditions. Izv Akaad Nauk 1958;8:26-31.

[21] Oliver J, Cervera M, Oller S, Lubliner J. Isotropic damage models and smeared crack analysis of concrete. In: Proc 2 nd int conf on computer aided analysis and design of concrete structures: Zell am See; 1990. p. 945-58.

[22] Lemaitre J, Chaboche JL. Aspects phénoménologiques de la rupture par endommagement. J Appl 1978;2:317-65.

[23] Chaboche JL. Continuum damage mechanics: Part I-general concepts. J Appl Mech 1988:55:59-64.

[24] Chaboche JL. Continuum damage mechanics: Part II-damage growth, crack initiation, and crack growth. J Appl Mech 1988;55:65-72.

[25] Simo JC, Ju JW. Strain- and stress-based continuum damage models-I. formulation. Int J Solids Struct 1987;23:821-40.

[26] Simo JC, Ju JW. Strain- and stress-based continuum damage models-II. computational aspects. Int J Solids Struct 1987;23:841-69.

[27] Kupfer H, Hilsdorf H, Rush H. Behaviour of concrete under biaxial stresses. J American Concrete Inst 1969;66:656-66.

[28] Mazars J, Pijaudier-Cabot G. Continuum damage theory-application to concrete. J Eng Mech 1989;115:345-65.

[29] Maugin GA. The thermodynamics of plasticity and fracture. Cambridge University press; 1992.

[30] Willam KJ. Constitutive models for engineering materials. In: Robert AM, editor. Encyclopedia of physical science and technology. New York: Academic Press; 2001. p. 603-33.

[31] Martinez X. Micro mechanical simulation of composite materials using the serial/parallel mixing theory. Ph.D. thesis. Barcelona: Universidad Politécnica de Cataluña; 2008.

[32] Martínez JJ, Mecánica Newtoniana. Barcelona: Ediciones UPC; 2001

[33] www.inneo.es/index.php/es/proceso-de-montaje.html; 27/10/2010. 